\title{
KİTLE İLETİŞIM ARAÇLARI VE SUSKUNLUK SARMALI
}

Yrd. Doç. Dr. Hayat Avcı BOZ*

\section{GIRIS}

İnsan yaşamının ve ilişkisinin temel koşulu olan iletişim, insan faaliyetlerini anlatır. İnsanla birlikte gerçek zaman ve gerçek yerde olan sosyal bir olgudur. Belli bir ort am ve koşullar altında oluşur ve sürer.

Insanlar, içinde oldukları dünyayı iletişimle biçimlendirir, anlamlandırırlar. $\mathrm{Bu}$ anlamlandırma ve biçimlendirmeyi; diğer insanlarla gerçekleştirdikleri karşılıklı iletişimle; ayrıca kitle iletişim araçlarının iletileriyle yaparlar. Kişilerarası iletişime göre oldukça geniş, ayrışı ve anonim bir kitleye seslenen ve genel olarak tek yönlï bir ileti akışının olduğu kabul edilen kitle iletişimi; kitap, dergi, gazete, radyo, televizyon ve internet gibi araçların kullanılması yoluyla gerçekleştirilir.

Genelde dönütün olmaması ya da çok geç ve zayıf olması nedeniyle antidemokratik bir iletişim türü olarak da nitelenen kitle iletişimi ile ilgili çok sayıda kuram geliştirilmiştir. Kitle iletişimi sürecini tanımlamak veya açıklamak üzere geliştirilmiş bu kuramlar içinde; eleştirel araştırmalarla yakınlan bulunan ve kitle iletişim araçlarının topluma etkilerinin uzun vadeli ve dolaylı olduğunu kabul eden, medyanın örtük olarak ideolojik taşıması, kanaat iklimi oluşumu, toplum içinde farklilaşan bilgi ve genel olarak kültür üzerinde duran Gündem Belirleme, Bağımlılık, Bilgi Gediği ve Suskunluk Sarmalı Kuramları bu özellikleriyle diğer kuramlardan ayrilırlar.

Bunlardan Suskunluk Sarmalt Kurami; Elisabeth Noelle-Neumann'ın geliştirdiği ve sınadığ , kamuoyunu ele alan daha büyük bir kuramın bir ilkesidir ve kitle iletişimi için oldukça önemlidir çünkü; kitle iletişim araçlarının birèyleri,

* A.Ü. Eğitim Bilimleri Fakültesi, Eğitim Bilimleri Bölümü Öğretim Üyesi. 
toplumu susturabilme, kimi gruplara da konuşma cesareti verebilme gücü üzerinde durur.

Bu çalışmada Suskunluk Sarmalı Kuramı'nın oluşum ve gelişiminde sonuçlarından büyük ölçüde yararlanılan sosyal psikoloji alanındaki "sosyol etki ve uyma" üzerine yapılan iki araştırma ve Festingerin bilişsel çelişki kuramı ile kitle iletişim araçları-suskunluk sarmalı ilişkisi açıklanacaktır.

\section{Kitle İletişim Araçları ve Suskunluk Sarmalı İlişkisi}

Kitle iletişim araçlarının belirli konu başlıklarını kamunun görüş ve tartışma alanından uzaklaştırma yeteneği üzerinde duran Suskunluk Sarmal Kuramı (Spiral of Silence) Alman sosyolog Elisabeth Noelle-Neumann tarafindan geliştirilmiştir. Uzun bir süredir geliştirilen ve sınanan $(1974 ; 1984 ; 1991)$ bu kuram dört öge arasındaki etkileşimle ilgilenir. Bu ögeler; kitle iletişimi, kişilerarası iletişim ve toplumsal ilişkiler, düşünncenin bireysel olarak açıklanması, bireylerin toplumsal çevrelerinde onlan çevreleyen düşünce ortamı hakkında sahip oldukları algılamadır (Alemdar ve Erdoğan, 1998, s.294).

Suskunluk Sarmall Kuramı, kişisel düşüncenin başkalarının ne düşündüğüne bağlı olduğunu ele alan temel sosyo-psikolojik düşünceden kaynaklanır ve şu varsayımlara dayanır (Mutlu, 1988, s.321; Mc Quail ve Windahl, 1997, s.135):

1. İnsanlar belli bir görüşü benimsemede yalnız olduklarını düşünüyorlarsa, bunu açik olarak dile getirmekten kaçınırlar, ancak bu görüşlerinin paylaşıldığını ya da destek göreceğini düşünüyorlarsa çevrelerindeki diğer insanlarla bu görüşleri hakkında konuşurlar.

2. Birey belli bir görüşün toplumda ne kadar geçerli olduğunu saptamada kitle iletişim araçlarını bir ölçüt olarak kullanabilir. Benimsediği görüş̧ bu araçlarda yeteri düzeyde yer almıyor, dile getirilmiyorsa, bunun yeterince kabul gören bir görüiş olmadığı sonucuna varır.

3. Iletişim araçlarının hemen hepsi az ya da çok tekelci bir şekilde aynı kanılan dile getirme eğiliminde olup, insanlan toplumdaki kanı iklimine ilişkin çoğu kez yanlış bir görüntüyle başbaşa bırakmaktadırlar. Buradan hareketle;

4. Belli bir görïşe sahip birçok insan, toplumdan, bulunduğu çevreden dışlanma korkusuyla görüşünü savunamayacaktır. Sus kun kalındıkça bu 
görüş olduğundan daha az yaygın ve geçerli sayılacak ve bu durum ise bir suskunluk sarmalının oluşmasına neden olacaktır. Genel-geçer görüşlerden farklı görüşleri olan insanlar giderek seslerini duyurmada daha az istekli olacak ve iletişim araçlarının görüşü giderek baskın ve doğru olarak algılanacaktır.

Suskunluk Sarmalı Kuramının geliştirilmesinde İkinci Dünya Savaş1 sonrasında Amerika'da gerçekleştirilen sosyal etki araştırmaları önemli yer tutmaktadır. Özellikle sosyal psikolog Solomon Asch ve daha sonra Stanley Milgram'ın sosyal etki ile ilgili deneysel araştırmaları ile Festinger'in Bilişsel Çelişki Kuramı oldukça önemlidir.

1950'li yılların başında Asch tarafindan elli kezden fazla uygulanan deneyde; deneklerden, üç değişik boydaki çizgiden hangisinin örnek olarak verilen çizgiye en yakın uzunlukta olduğunu bilmeleri istenmiştir. Verilen çizgilerden yalnızca birinin uzunluğu örnek çizgiyle aynıdır ve bu oldukça açık bir şekilde görülmektedir. Her kart çifti gösterildiğinde, araştırmacının denek rolü yapan yardımcıları sırasıyla yargılarını söylemekte ve esas deneğe söz surası en sonda gelmektedir. İlk birkaz kart çiftinde deneğin güvenini kazanmak için doğruyu söyleyen sahte denekler, sona doğru hep yanlış cevap verirler. Kendine sira gelinceye kadar, gerçek denek sandığı diğer kişilerin verdiği yanlış cevaplardan rahatsız olan deneğin sıra kendine gelince gerçeye aykırı olduğunu bildiği halde diğerlernin söylediklerini tekrarladığı görülmüş̧tür. Çok sayıda deneğin kullanıldığı bu araşırmada her üç denekten biri (\%35) yanlış olduğunu bile bile diğerlerinin kararlarına uymuştur (Kağıtçıbaş1, 1977, ss.56-57; Bilgin, 1988, ss.32-33; Neumann, 1988, ss.63-46). Bu ise şu anlama gelmektedir: Çoğu insan, çok da umurlarında olmayan, önemsiz bir konuda, çıkarlarnı zedelemeyecek bir durumda bile, çoğunluğun yanlış olduğundan şüphe edemeyecekleri görüşlerine katılmaktadırlar. Neumann'a göre bunun nedeni açıktır: "başkalarından bir şey öğrenmeyi umuyor olamaz, olsa olsa dışlanmaktan korkuyordur" (1998, s.65).

Bu deneyin ardından Milgram'ın, insanların sosyal etkiye ne dereceye kadar boyun eğeceklerini test eden "itaat" deneyinde, tanımadığı birine zarar verme emri alan bir bireyin bu emre uyup-uymayacağ 1 ya da ne dereceye kadar uyacağ incelenmiştir. Cezanın öğrenmeye etkisini ölçmek amacıyla bir deney yapıldı̆̆ını ve kendisine tesadüfi olarak öğretmen rolünün düştügünü sanan deneklere; öğrenci rolünde olan, ancak kendilerinin sahte olduğunu bilmedikleri deneğe, sordukları sorulara aldıkları her yanlış yant için giderek artan elektrik şoku (gerçek değil) vermeleri gerektiği söylenmiştir. 15 volttan başlayıp, 15'er volt artarak 450 volta kadar çıkan elektrik şokunu öğrenciden gelecek her yanlış yanıtta 15 volt arttırarak kullanmalan istenen deneklerin \%65'I öğrencinin kalp 
hastası olduğu (gerçek değil) bilgisine sahip olmalarına rağmen, araştırmacının "devam edin" uyarısına uyarak 450 volta ulaşan bir elektrik şokunu, suçu olmayan bir insana istemeden de olsa "emre itaat" sonucu vermişlerdir (Kağıtçıbaşı, 1977).

Suskunluk Sarmalt Kuramının oluşumunda önemli etkileri olan bu sosyal etki ve uyma araştırmalarının sonuçları yanında Festinger'in Bilişsel Çelişki Kuramı da oldukça önem taşır.

Festinger'e göre; eğer kişinin sahip olduğu bir inanç, bilgi ya da tutum, yine o kişinin sahip olduğu bir başka inanç, bilgi ya da tutumun tersini gerektiriyorsa, bu iki inanç, bilgi ya da tutum arasında bilişsel çelişki vardır (Kağıtçıbaşı, 1977) ve kurama göre bu tür bilişsel çelişkiler kişiye sıkıntı veren durumlar olduğundan, kişide bu çelişkiden kurtulmak için bir güdülenme meydana gelir.

Neumann'ın Suskunluk Sarmalı Kuramı da temelde Festingerin bilişsel çelişki kuramının psikolojik alandan alınıp sosyolojik alana uygulanmasidır (Alemdar ve Erdoğan, 1998, s.205). Bilişsel çelişki kuramı, özellikle kişinin, tutumuna ters düşen bir davranışı yapmış olduğu durumlardaki uyuşmazlığı ele almaktadır. Kurama göre böyle durumlarda, eğer kişi yaptığı davranış için geçerli (zorlayıcı) bir dış neden bulamazsa bilişsel uyuşmazlık oluşur ve kişi bu uyuşmazlıktan kurtulmak için bir iç neden arayarak tutumunu davranışı doğrultusunda değiştirir. Bir dış neden bulursa tutum değişimi gerekmeyecektir. "İtaat" ile uyma davranışında, bu davranışı makul gösterecek zorlayıcı bir dış neden söz konusu olduğundan, bilişsel uyuşmazlık oluşmayacak ve kişinin gerçek tutumu davranı̧̧ı doğrultusunda değişime göstermeyecektir.

Bilişsel uyuşmazlıktan kaçış ve denge arayışı psikolojik veya sosyopsikolojik yaklaşımda, kişinin kendi kafasında, kendi kendisiyle iletişim sürecinde oluşturduğu bir kişisel psikolojik dengedir. Neumann'da bu denge arayışı, kişinin yaşadığı ortamdaki egemen fikirlere yönelmesi ve uyumsuzluk yaratan veya azınliktan fikirlerden kaçınması; eğer böyle bir fikir taşıyorsa egemen fikirler karşısında susmayı tercih etmesi biçiminde, kişinin kendi iç dünyasında denge ve uyum aramasından uzatılarak, dış dünyadaki dengeye uygulanmıştır (Alemdar ve Erdoğan, 1998, s.205).

İnsanları uyma davranışı göstermeye iten oldukça önemli nedenler vardır. Bilişsel çelişki kuramına göre insanın uyuşmazlıktan kurtulup denge içinde olma gereksinmesi önemli bir nedendir. Bu gereksinmenin dışında insanların çoğu kez diğer insanlar tarafından kabul edilme, dışlanmama, cezalandırılmama gibi nedenlerle uyma davranışı gösterdkleri bilinmektedir. Toplumsal bir varlık olan insanın ait olduğu çevreden ve daha büyük bir çevre olan toplumdan 
soyutlanmaması onun asgari bir uyum göstermesini zorunlu kılar. Diğer insanlardan farklı konuma düşmemek, dışlanmamak dürtüsüyle insanlar, sahip oldukları görüşlerin, kanaatlerin, inançlann ne ölçüde kabul gördügüünü belirlemek için diğerlerine bakma ve gözleme eğilimindedirler. Bunu yaparken iki kaynaktan yararlanırlar. Birincisi doğrudan gözlemledikleri çevre, ikincisi, kitle iletişim araçlandır.

Birçok durumda bireyin kitle iletişim araçlarının sunduğu haberlerden başka bilgi kaynağı yoktur ve bu kaynak da genelde dışlama tehdidi saçmanın (Neumann, 1998) yanında en önemli görevi olan bilgilendirme işlevi içinde dahi toplumun eğilimlerini bozma veya ilgiyi başka tarafa yöneltme gibi bir özellik göstermektedir (Groombridge, s.86).

Tekelci bir doğaya sahip kitle iletişim araçlarının bu doğasından kaynaklanan alışılmış bir çalı̧̧ma yöntemi ve araçlar arasında yüksek derecede bir anlaşma ve uyum vardır (Alemdar ve Erdoğan, 1998). Kitle iletişim araçlarındaki bu tek seslilik ve tek boyutluluk bireye, sunulan mesajlar arasından seçim yapma şansı tanımamaktadır. Ayrıca, kitle iletişim araçlarının belirli kanaat ve konuları daha ön plana çıkarmak şeklinde yerine getirdiği "dillendirme" işlevi vardır. Bu anlamda kitle iletişim araçları gündem oluştururken çok sayıda olay arasından yaptıkları seçmede egemen görüşe karşı çıkan kişi ve gruplan dışlar ve yerleşik düzenin savunulucuğunu yapar (Akarcall, 1997, s.31; Uslu, 2000, s.26). Bu nedenle belirli bir kanaat ya da davranış biçiminin yandaşları ve karşıtları kitle iletişim araçlarında eşit bir biçimde "dillendirilme" olanağına sahip değildirler. Tartışmah bir konuuda kitle iletişim araçlarında baskın olarak temsil edilen bir kanaat kendini daha kolay kabul ettirir, çünkü yandaşlarına gereken slogan ve ifadeler sunulmaktadır. Görüşleri kitle iletişim araçlarına pek az ya da hiç temsil edilmeyen karşıtlarına göre, bu insanlar için, kamu içinde konuşmak çok daha kolay olmaktadır (Neumann, 1998).

Adil dağıtılmayan bir bilginin antidemokratik bir toplumda yalnızca mevcut güç ilişsilerinin pekiştirilmesine yarayacağını belirten Dündar, enformasyon akışını kontrol edenlerin, ellerindeki bilgiyi egemenliklerini yaygınlaştırı sağlamlaştırmada kullandıklarını da eklemektedir (1999, s.120). Karşıt düşüncelerin dışlanması ve önemsizleştirilmesi sürecinin çoğu kez çok doğal işlediğini belirten Herman ve Chomsky; dürüstçe ve iyi niyetle çalışan medya çalışanlarının dahi haberleri nesnel ve profesyonel haber ölçuitlerini temel alarak seçip yorumladıklarına kendilerini inandırdıklarını savunurlar (1999, s.22).

İnsan Hakları Evrensel Bildirgesi'nin 19. Maddesi: "Herkes görüş ve ifade özgürlüğü hakkına sahiptir; bu hak başkalarınca karışılmadan görüş sahibi olmayı ve sinır tanımaksızın her medya ile bilgi ve fikirleri aramayı, almayı ve 
göndermeyi içerir" der (Keane, 1999, s.131). Bu bağlamda kitle iletişim araçlarının belli konuları ve sorunları ve bunların tartışmasını halkın görmesinden uzaklaştırma özelliğinin önemi üzerinde duran Neumann, bir görüş biçiminin egemenliğini algılamanın çoğu kez gerçekte halk çoğunluğunun böyle bir görüşe sahip olmadığıyla çok az bir ilişkisi olduğunu ve algılanmış çoğunluk fikirlerinin çoğu kez yalnızca bir azınlık tarafından tutulduğunu, bununla beraber bir görüş biçiminin çoğunlukta olduğu algısının sarmal süreci harekete geçirdiğini ve bu süreçte aksi görüşe sahip halkın, sessiz durmaya başladığını hatta bu sessizliğin çocuklarımıza dostlarımıza kadar uzandığını ve onlara gerçek düşüncelerini söylememelerinin öğretilmesine kadar gittiğini (Keane, 1999, s.56) ve algılanmış çoğunluk görüişünün egemen gerçek görüş olarak kurulduğunu belirtir (Alemdar ve Erdoğan, 1998).

Althusser hiçbir smıfin devlet erkini, aynı zamanda devletin ideolojik aygtlarında hegemonyasını kullanmaksızın, uzun süre elinde tutamayacağını belirtir. Kitle iletişim araçlarının da içinde bulunduğu bu aygıtlar sınıf savaşımıyla elde edilecek kurumlar olmanın yanısıra sınıf savaşımınm yürütüldüğü bir alandır (Mutlu, 1998, s.92) ve devlet iktidarını elde tutmanın kaçınılmaz şartıdır (Akdoğan, 1995, s.23). İdeoloi kuramları her tür iletişimin ve tüm anlamların toplumsal-siyasal bir boyutunun olduğunu ve bunlarm toplumsal bağlamlar dışında anlaşılamayacaklarını vurgular. $\mathrm{Bu}$ işleyiş de her zaman statü-koyu kayırır, çünkü, iktidarı ellerinde bulunduran sınıflar yalnızca malların değil aynı zamanda fikir ve anlamların da üretimini ve dağıtımını kontrol ederler (Fiske, 1996). Düşünce üretiminin de mal üretimi gibi ticarileştiği ülkelerde basılan, reklamı yapılan, dağıtılan ve satılan düşünceler egemen düzenin egemen düşünceleri olduğu için üretimde tek taraflı bir egemenlik sağlanır. Dolayısıyla, Marx'ın da belirttiği gibi, genel olarak, düşünceleri üretme araçlarına sahip olmayanlar, bu araçlara sahip olanların düşüncelerinin egemenliğine tabidir (Erdoğan, 1995, s.44, Erdoğan 1997, s.286).

Insan dışlanmamak için nasıl davranması gerektiğine özellikle de köklü değişimlerin yaşandığı dönemlerde çok dikkat etmek zorunda kalmıştır. Güvenliği elinden alınan birey bu dönemlerde cezalandırılmamak, sahip olduklarını kaybetmemek için susmayı tercih etmiştir. Keane, özellikle bu dönemlerde kitle iletişim araçlarının oldukça belirgin bir siyasal rol oynadıklarını ve halk arasında bunalım duygusunu kollektifleştirerek ve bunalımın tedavisi için sıkı önlemler alınması gerektiği yolundaki resmi iddiaları yayarak, örtïk bunalımın açık bunalım haline dönüşmesini sağladıklarını belirtir (1999, s.100). $\mathrm{Bu}$ nedenledir ki; radyo televizyon kanallarının bu denli yaygınlık göstermediği ve yayıncilığın çoğunlukla devlet tekelinde olduğu, demokrasinin yerleşmediği ülkelerde çeşitli dönemlerde devlet yönetimini darbe veya benzeri yollarla ele geçirmeye çalışan ya da ele geçirenlerin denetim altına almak istedikleri kurumların başında radyo-televizyon istasyonları gelir. 
1980 Mc. Bridge Komisyonu Rapor'unda UNESCO, kitle iletişim araçlarının ezilmiş halkların özgürlük, bağımsızlık ve iletişim haklarının korunması yolunda bir rol ve sorumluluğa sahip olması gerektiğini vurgulamakta (Özdemir, 1998, s.15) ancak, kapitalist iletişim firmaları ekonomik çıkarlarını herşeyin üstünde tutmanın yanında, siyasal anlamda özel teşebbüs ideolojisine ters düşen ideolojik sunumlardan kaçınma, kendine materyal gelir sağlayan siyasal güçlerin hoşuna gitmeyecek haber vermeme veya yorumlar yapmama sorumluluğu duyarken, halkla ilişkilerinde kendilerini sorumlu tutacak bir güç ilişkisinden arındırmaktadırlar (Erdoğan, 997, s.287).

Bireyin kendi görüşlerinin, inançlarının toplumda ne kadar kabul gördüğünü belirlemede başvurduğu en önemli bilgi kaynağı olan kitle iletişim araçlan küçüik bir azınlığın çıkarları doğrultusunda yayın yapmayı sürdürdükçe büyük bir çoğunluğun kendi görüşlerini özgürce yayma cesaretini kıracaktır. Çünkü egemen azınlığın görüşü her birey tarafından büyük çoğunluğun görüşü olarak algılandığında dışlanma, var olan çıkarlarını yitirme, cezalandırılma korkusuyla insanlar susacak ve bu suskunluk kamusal olarak algilanabilecek biçimde gelişmeye başlar başlamaz, toplumsal katılım bu sürece hız verecek ve devamını sağlayacaktır. Görüşlerinin toplumun geneliyle uyum içinde olduğundan emin olanlar kamusal alanlardaki konuşmalara kendinden emin bir biçimde katılacak ve düşüncelerini açığa vuracaktır. Azzınlıkta olduklanıı düşünenler ise, daha dikkatli davranacak ve susmayı tercih edecek, böylece toplum içinde gerçekte olduğundan daha zayif bir izlenim yaratacaklardır.

Suskunluk Sarmalı Kuramına göre (Neumann, 1998, s.163) ancak dişlanma korkusu olmayanlar ya da dişlanmayı göze alanlar toplumu değiştirme olanağına sahiptir ve bunlar da geleceğin yollarını döşeyen marjinaller, sanatçılar, reformcular ve bilim adamlarıdır.

\section{Sonuç}

Bireyin kanaat belirlemede başvurduğu en önemli kaynak olan kitle iletişim araçlan; siyasi iktidar baskısının olmadığı, ticari kaygıların herşeyin üstünde tutulmadığı, egemen görüşlerin sözcülüğünü yapmak yerine farklı görüşlerin özgürce iletildiği bir nitelik kazanıp, yaygınlaştıkça, suskunluk sarmallarının oluşumu büyük ölçuide engellenecek ve toplum kahramanlara gereksinme duymayacaktır. 


\section{KAYNAKÇA}

Akarcal1, Sezer. Türkiye'de Kamusal Radyodan Özel Radyo ve Televizyona Geçiş Süreci. Ankara: Punto Matbaacılık, 1997.

Akdoğan, Yalçın. Görsel İktidar, İstanbul, İnsan Yayınları, 1995.

Alemdar, Korkmaz ve İıfan Erdoğan. Başlangıcından Günümüze İletişím Kuram ve Araştırmaları. Ankara. Erek Ofset, 1998.

Bilgin, Nuri. Sosyal Psikolojiye Giriș. Editör: Nuri Bilgin. İzmir: Ege Üniversitesi Edebiyat Fakültesi, 1988.

Erdoğan, İrfan. Dünyanın Çarpık Düzeni: Uluslararası İletişim. Ankara: Kaynak Yaymlan, 1995.

Dündar, Can. Yağmurdan Sonra. Onuncu Baskı. Ankara: IMMGE Kitabevi, 1999.

Erdoğan, İrfan. İletişim Egemenlik Mücadeleye Giriş. Birinci Baskı. Ankara: IMMGE Kitabevi, 1997.

Fiske, John. İletişim Çalışmalarına Giriş. Çeviren: Süleyman İrvan. Birinci Basım. Ankara: Bilim ve Sanat Yayınları/ARK, 1996.

Groombridge, Brian. Televizyon ve İnsanlar. Demokratik Katılım Açısından Medya . Çeviren: İbrahim Şener. İstanbul: DER Yayınları, (Basım tarihi belirtilmemiş).

Herman, Edward S. ve Noam Chomsky. Medya Halka Nasıl Evet Dedirtir: Kitle İletişim Araçlarının Ekonomi Politiği. İkinci Baskı. Yayına Hazırlayan: İsmail Kaplan. Çevirenler: Berfu Akyoldaş, Tamara Han, Metin Çetin, İsmail Kaplan. İstanbul: Minerva Yayınları, 1999.

Kağıtçıbaşı, Çiğdem. İnsan ve İnsanlar: Sosyol Psikolojiye Giriş. Íkinci Baskı. İstanbul: Duran Ofset Matbaacilık Sanayi A.Ş., 1977.

Keane, John. Medya ve Demokrasi. Üçüncü Basım. Çeviren: Haluk Şahin. İstanbul: AYRINTI Yayınları, 1999.

Mq Quail, Denis ve Sven Windahl. Kitle İletişim Modelleri. Birinci Baskı. Çeviren: Konca Yumlu. Ankara: İMGE Kitabevi, 1997.

Mutlu, Erol. İletişim Sözlüğü. Üçüncü Basım. Ankara: Bilim ve Sanat Yayınlan, 1998.

Neuman, Elisabeth Noelle. Kamuoyu-Suskunluk Sarmalmm Keşfi. Birinci Baskı. Çeviren: Murat Özkök. Ankara: DOST Kitabevi, 1998.

Özdemir, Sadi. Medya Emperyalizmi ve Küreselleşme. İstanbul: Timaş Yayınları, 1998.

Uslu, Zeynep Karahan. Televizyon ve Kadın. İstanbul: ALFA, 2000. 